\title{
PENGEMBANGAN KURIKULUM MATEMATIKA UNTUK MENINGKATKAN KEMAMPUAN SISWA DALAM PENALARAN DAN PEMECAHAN MASALAH
}

\author{
Yogi Anggraena \\ Pusat Kurikulum dan Pembelajaran, Balitbang, Kemdikbud \\ yogi.anggraena@kemdikbud.go.id
}

\begin{abstract}
:
The Trending topic in International Mathematics and Science Study (TIMSS) and the Program for International Student Assessment (PISA) have become a new standard for mathematics learning. One of the objectives of the study from TIMSS and PISA is to know the students' abilities in reasoning, identifying, and understanding, and using the basic mathematics needed in daily life. Or in other words, students must have mathematical literacy. The concept of mathematical literacy is intended the ability of individuals to formulate, use, and interpret mathematics in various contexts. This includes mathematical reasoning and using mathematical concepts, procedures, facts, and equipment to describe, explain, and predict phenomena or events (OECD, 2013). Indonesia has participated in TIMSS and PISA studies several times, from the TIMSS and PISA study results, it shows that students have not been able to develop optimally about their thinking abilities in mathematics schools and are still low in ability (1) to understand complex information, (2) theory , analysis and problem solving, (3) using tools, procedures and problem solving and (4) conducting investigations. In 2014, the National Council of Teachers of Mathematics (NCTM) stated that learning mathematics today is still too formal, lacks connection with the meaning, understanding, and application of mathematical concepts, and fails to give sufficient attention to the ability of reasoning and solving problem. These results indicate that there needs to be a change in curriculum orientation, which is not to burden students with content but prioritize the aspects of essential abilities needed by all citizens to participate in developing their country in the 21st century. Therefore it is necessary to develop a mathematics curriculum that enhances students' abilities in reasoning and problem solving in order to improve the quality of mathematics for students knowledge and skill in this global era.
\end{abstract}

Keywords: curriculum, mathematics, reasoning, problem solving.

\section{PENDAHULUAN}

Kurikulum matematika saat ini pada dasarnya (dibanyak negara) selaras dengan dengan harapan yang diuraikan dalam kurikulum Amerika Serikat (United States of America National Council of Teachers of Mathematics Standards), yaitu suatu organisasi profesi pendidikan matematika di Amerika Serikat yang sangat berpengaruh, yang sejak tahun 1980an telah menyerukan diadakannya perombakan secara menyeluruh terhadap praktek pembelajaran matematika di banyak negara, termasuk di Amerika Serikat sendiri, yang antara lain mendorong agar praktek pembelajaran matematika beralih dari pembelajaran yang bersifat teacher-centered ke pembelajaran yang bersifat student-centered, dan mengubah para siswa yang sebelumnya merupakan pembelajar yang pasif (passive learners) menjadi siswa merupakan pembelajar yang aktif (active learners) NCTM (Council, 1989), (Ferrini-Mundy \& Martin, 2000). Dalam pembelajaran matematika, seperti 
dikemukakan dalam NCTM (Council, 1989), (Ferrini-Mundy \& Martin, 2000) diharapkan para siswa akan meningkat kemampuannya dalam hal penalaran (reasoning), pemecahan masalah (problem solving), komunikasi matematis (mathematical communication), koneksi-koneksi matematis (mathematical connections), dan dalam hal menggunakan representasi matematis(mathematical representation). Untuk terbentuknya kemampuan koneksi matematik tersebut, dalam NCTM Standards (Ferrini-Mundy \& Martin, 2000) dijelaskan bahwa pembelajaran matematika harus diarahkan pada pengembangan kemampuan berikut: (1) memperhatikan serta menggunakan koneksi matematik antar berbagai ide matematik, (2) memahami bagaimana ide-ide matematik saling terkait satu dengan lainnya sehingga terbangun pemahaman menyeluruh, dan (3) memperhatikan serta menggunakan matematika dalam konteks di luar matematika (Suryadi, 2011).

Studi Trend in International Mathematics and Science Study (TIMSS) dan Program for International Student Assessment (PISA) telah menjadi standar baru bagi pembelajaran matematika. Salah satu tujuan studi dari TIMSS dan PISA yaitu mengetahui kemampuan siswa dalam penalaran, mengidentifikasi, dan memahami, serta menggunakan dasar-dasar matematika yang diperlukan dalam kehidupan sehari-hari. Atau dengan kata lain, siswa harus memiliki literasi matematika. Konsep tentang literasi matematika dimaksudkan kemampuan individu untuk memformulasikan, menggunakan, dan menginterpretasikan matematika dalam berbagai konteks. Hal ini termasuk penalaran matematis dan menggunakan konsepkonsep matematika, prosedur, fakta, dan peralatan untuk menggambarkan, menjelaskan, dan memprediksi penomena atau peristiwa (OECD, 2013).

Survei TIMMS yang dilakukan oleh The International Association for the Evaluation and Educational Achievement (IAE) berkedudukan di Amsterdam, mengambil fokus pada domain isi matematika dan kognitif siswa. Domain isi meliputi Bilangan, Aljabar, Geometri, Data dan Peluang, sedangkan domain kognitif meliputi pengetahuan, penerapan, dan penalaran. Survei dilakukan setiap 4 (empat) tahun yang diadakan mulai tahun 1999, khusus untuk siswa berusia 14 tahun. Hasil analisis lebih jauh untuk studi TIMSS menunjukkan bahwa soal-soal yang digunakan untuk mengukur kemampuan siswa dibagi menjadi empat kategori, yaitu: low mengukur kemampuan sampai level knowing, intermediate mengukur kemampuan sampai level applying, high mengukur kemampuan sampai level reasoning, dan advance mengukur kemampuan sampai level reasoning with incomplete information. Sedangkan studi PISA, yang diselenggarakan oleh Organization for Economic Cooperation and Development (OECD) sebuah badan PBB yang berkedudukan di Paris, bertujuan untuk mengetahui literasi matematika siswa. Fokus studi PISA adalah kemampuan siswa dalam mengidentifikasi dan memahami serta menggunakan dasar-dasar matematika yang diperlukan dalam kehidupan seharihari. Studi dilakukan setiap 3 (tiga) tahun yang dilakukan mulai tahun 2000, untuk siswa berusia 15 tahun. Berdasarkan analisis hasil PISA 2009, ditemukan bahwa dari 6 (enam) level kemampuan yang dirumuskan di dalam studi PISA, hampir semua siswa Indonesia hanya mampu menguasai pelajaran sampai level 3 (tiga) saja, sementara negara lain yang terlibat di dalam studi ini banyak yang mencapai

Alifmatika: Jurnal Pendidikan dan Pembelajaran Matematika, Desember 2019, Vol. 1, No. 1 
level 4 (empat), 5 (lima), dan 6 (enam) (Tohir, 2016). Adapaun Hasil PISA Indonesia pada tahun 2018 turun ketimbang hasil PISA pada tahun 2015, yaitu untuk kategori matematika, Indonesia berada di peringkat 7 dari bawah (73) dengan skor rata-rata 379. Sedangkan pada tahun 2015 Indoensia mendapatkan skor rata-rata 386 dari 70 Negara (Tohir, 2019).

Kelemahan pembelajaran matematika saat ini para siswa tidak dapat menghubungkan konsep-konsep matematika di sekolah dengan pengalaman mereka sehari-hari. Pembelajaran matematika terlalu formal, kurang mengkaitkan dengan makna, pemahaman, dan aplikasi dari konsep-konsep matematika, serta gagal dalam memberikan perhatian yang cukup terhadap kemampuan penalaran dan pemecahan masalah (Leinwand, 2014). Menurut Tohir (2017) mengatakan bahwa masalah matematika adalah suatu masalah yang membutuhkan teknik tertentu untuk memecahkannya baik berupa soal rutin maupun non rutin. Oleh karena itu perlu dikembangkan kemampuan praktis matematika seperti pemecahan masalah, membuat hubungan, memahami berbagai representasi dari ide-ide matematika, mengkomunikasikan proses pemikiran mereka, dan penalaran (Tohir, Susanto, Hobri, Suharto, \& Dafik, 2018).

\section{PEMBAHASAN}

Standar kurikulum matematika seharusnya menekankan hubungan (connection) sebagai salah satu proses penting dalam pembelajaran matematika. Pembelajaran harus membuat siswa dapat mengenal dan menggunakan dalam konteks di luar matematika. Hal ini termasuk membuat hubungan terhadap"dunia nyata”, yaitu dunia di luar kelas. Oleh karena itu, guru diharapkan menyiapkan situasi dunia real dan konteksnya untuk siswa guna membuat ide-ide matematika masuk akal, bisa diterima siswa. Dengan demikian akan memberikan kesempatkan kepada siswa untuk mengenal dan mengapresiasi hubungan matematika dengan kehidupannya. Guru sekarang didorong untuk membantu siswanya membuat hubungan yang lebih realistis antara matematika dengan kehidupan sehingga membuat matematika lebih bermakna. Tetapi menghubungkan matematika dengan kehidupan sehari-hari tidak selalu mudah. Hal ini berarti para guru juga membutuhkan kemampuan untuk dapat mengenali dan memahami tentang hubungan dan aplikasi matematika, yang dapat digunakan untuk mengembangkan pembelajaran matematika. Siswa membangun sendiri pengetahuan melalui proses investigasi tersebut.

Kecakapan atau kemahiran matematika merupakan bagian dari kecakapan hidup yang harus dimiliki peserta didik terutama dalam pengembangan penalaran, komunikasi, dan pemecahan masalah yang dihadapi dalam kehidupan peserta didik sehari-hari. Oleh karena itu Mata pelajaran matematika perlu diberikan kepada semua peserta didik mulai dari sekolah dasar, untuk membekali peserta didik dengan kemampuan berpikir logis, analitis, sistematis, kritis, inovatif dan kreatif, serta kemampuan bekerjasama. Kompetensi tersebut diperlukan agar peserta didik dapat memiliki kemampuan memperoleh, mengelola, dan memanfaatkan informasi untuk hidup lebih baik pada keadaan yang selalu berubah, tidak pasti, dan sangat kompetitif. Dalam melaksanakan pembelajaran

Alifmatika: Jurnal Pendidikan dan Pembelajaran Matematika, Desember 2019, Vol. 1, No. 1 
matematika, diharapkan bahwa peserta didik harus dapat merasakan kegunaan belajar matematika.

Pendidikan matematika di sekolah diharapkan memberikan kontribusi dalam mendukung pencapaian kompetensi lulusan pendidikan dasar dan pendidikan menengah melalui pengalaman belajar, agar mampu:

a. memahami konsep dan menerapkan prosedur matematika dalam kehidupan sehari-hari;

b. melakukan operasi matematika untuk penyederhanaan, dan analisis komponen yang ada;

c. melakukan penalaran matematis yang meliputi membuat generalisasi berdasarkan pola, fakta, fenomena atau data yang ada, membuat dugaan dan memverifikasinya;

d. memecahkan masalah dan mengomunikasikan gagasan melalui simbol, tabel, diagram, atau media lain untuk memperjelas keadaan atau masalah;

e. menumbuhkan sikap positif seperti sikap logis, kritis, cermat, teliti, dan tidak mudah menyerah dalam memecahkan masalah.

Dalam usaha mencapai kemampuan di atas maka dalam dalam Kurikulum 2013 dilakukan penataan kompetensi yang tidak dibatasi oleh pemenggalan taksonomi proses berpikir (As'ari, Tohir, Valentino, Imron, \& Taufiq, 2017). Maka mulai dari tingkat SD, SMP, dan SMA, keluasan dan kedalaman dimensi pengetahuan meliputi: faktual, konseptual, posedural, metakognitif dan dimensi proses berpikir: mengingat, memahami, menerapkan, menganalisis, mengevalusi, mencipta. Lalu dalam mata pelajaran Matematika, dijabarkan ke dalam peta kompetensi sebagi berikut. 
Tabel 1. Peta Kompetensi pada Setiap Jenjang Pendidikan.

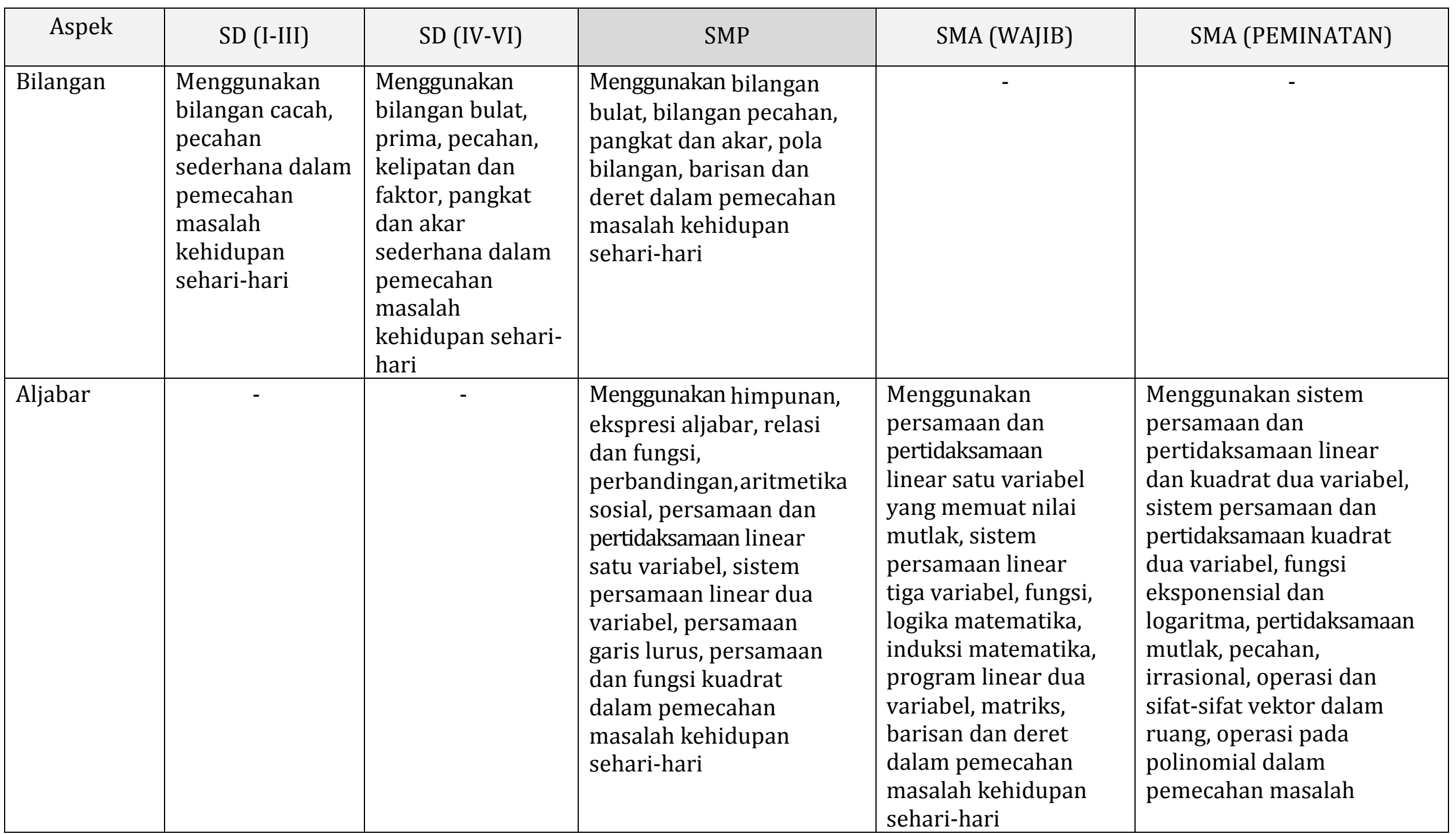


Pengembangan Kurikulum Matematika untuk Meningkatkan....

\begin{tabular}{|c|c|c|c|c|c|}
\hline Aspek & SD (I-III) & SD (IV-VI) & SMP & SMA (WAJIB) & SMA (PEMINATAN) \\
\hline $\begin{array}{l}\text { Geometri dan } \\
\text { Pengukuran }\end{array}$ & $\begin{array}{l}\text { Menggunakan } \\
\text { bangun datar } \\
\text { dan bangun } \\
\text { ruang } \\
\text { sederhana, } \\
\text { konsep satuan } \\
\text { (berat, panjang, } \\
\text { dan waktu), } \\
\text { dalam } \\
\text { pemecahan } \\
\text { masalah } \\
\text { kehidupan } \\
\text { sehari-hari }\end{array}$ & $\begin{array}{l}\text { Menggunakan } \\
\text { bangun datar dan } \\
\text { bangun ruang, } \\
\text { hubungan antar } \\
\text { garis, pengukuran } \\
\text { (berat, panjang, } \\
\text { luas, volume, } \\
\text { sudut, } \\
\text { waktu, kecepatan, } \\
\text { dan debit), letak } \\
\text { dan koordinat } \\
\text { suatu benda } \\
\text { dalam pemecahan } \\
\text { masalah } \\
\text { kehidupan sehari- } \\
\text { hari }\end{array}$ & $\begin{array}{l}\text { Menggunakan garis dan } \\
\text { sudut, bangun datar } \\
\text { (segiempat dan segitiga), } \\
\text { bangun ruang sisi datar, } \\
\text { bangun datar sisi } \\
\text { lengkung, lingkaran, } \\
\text { kesebangunan dan } \\
\text { kekongruenan,dan teorema } \\
\text { Pythagoras, transformasi } \\
\text { dalam pemecahan } \\
\text { masalah kehidupan } \\
\text { sehari-hari }\end{array}$ & $\begin{array}{l}\text { Menggunakan matriks } \\
\text { pada transformasi } \\
\text { geometri, bidang } \\
\text { datar, tranformasi } \\
\text { geometri, geometri } \\
\text { ruang dalam } \\
\text { pemecahan masalah }\end{array}$ & $\begin{array}{l}\text { Menggunakan irisan } \\
\text { kerucut (lingkaran, ellips, } \\
\text { parabola, dan hiperbola), } \\
\text { hubungan antar lingkaran, } \\
\text { garis singgung persekutuan, } \\
\text { dan luas daerah irisan dua } \\
\text { lingkaran dalam pemecahan } \\
\text { masalah }\end{array}$ \\
\hline $\begin{array}{l}\text { Trigonometr } \\
\text { i }\end{array}$ & - & - & - & $\begin{array}{l}\text { Menggunakan } \\
\text { perbandingan } \\
\text { trigonometri pada }\end{array}$ & $\begin{array}{l}\text { Menggunakan persamaan } \\
\text { trigonometri, rumus jumlah } \\
\text { dan selisih sinus dan }\end{array}$ \\
\hline
\end{tabular}




\section{Yogi Anggraena}

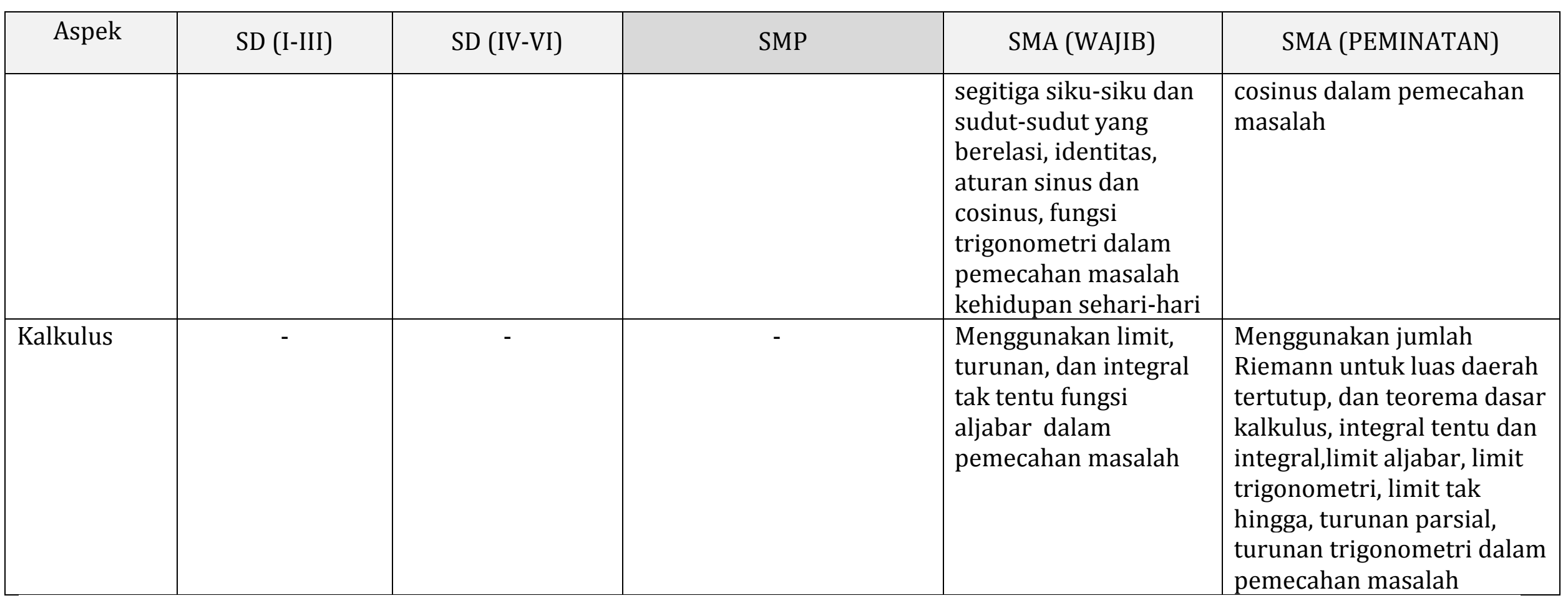

(Kemdikbud, 2015) 
Selanjutnya, agar kompetensi yang sudah disusun dapat terlaksana dengan baik, maka dalam proses pembelajaran matematika digunakan pendekatan saintifik yang dapat diperkuat dengan model-model pembelajaran, antara lain: Model Pembelajaran Kooperatif; Pembelajaran Kontekstual; Model Pembelajaran Penemuan Terbimbing; Project Based Learning; dan Problem Based Learning. Pendekatan saintifik disesuaikan dengan materi yang ada pada mata pelajaran matematika untuk mengembangkan pengetahuan, kemampuan berpikir, dan keterampilan melalui interaksi langsung dengan sumber belajar yang dirancang dalam silabus dan RPP. Dalam pembelajaran, siswa melakukan kegiatan belajar mengamati kejadian, peristiwa, situasi, pola, fenomena yang terkait dengan matematika dan mulai dikenalkan pemodelan matematika dalam berbagai bentuk; menanya atau mempertanyakan mengapa atau bagaimana fenomena bisa terjadi; mengumpulkan atau menggali informasi melalui mencoba, percobaan, mengkaji, mendiskusikan untuk mendalami konsep yang terkait dengan fenomena tersebut; serta melakukan asosiasi atau menganalisis secara kritis dalam menjelaskan keterkaitan antar konsep dan menggunakan, memanfaatkan dan memilih prosedur/algoritma yang sesuai, menyusun penalaran dan generalisasi, dan mengkomunikasikan apa yang sudah ditemukannya dalam kegiatan analisis.

Dalam pembelajaran matematika ini hal yang perlu ditekankan.

a. Aktivitas belajar di bawah bimbingan guru maupun mandiri dengan menggunakan konsep dan prosedur secara benar dan sistematis dengan mementingkan pemahaman daripada hanya mengingat prosedur.

b. Melatih kemampuan berpikir untuk membuat generalisasi dari fakta, data, fenomena yang ada.

c. Melatih keterampilan melakukan manipulasi matematika untuk menyelesaikan masalah.

d. Melatih keterampilan penalaran matematika.

e. Pembelajaran berbasis pemecahan masalah.

Berikut beberapa contoh pembelajaran yang dapat meningkatkan penalaran dan pemecahan masalah

Contoh 1. (untuk Siswa SD/MI)

Pak budi membeli sekeping tripleks seharga Rp 125.000. Karena dia minta tripleks tersebut dipotong menjadi 3 bagian yang sama, dia dikenakan biaya Rp 3500 sekali potong. Selanjutnya Pak Budi harus membayar biaya pengecatan sebesar $30 \%$ dari seluruh biaya setelah pemotongan. Toko memberikan tanda pembayaran sebagai berikut:

1 lembar tripleks @ Rp 125000

3xpemotongan@3500

Subtotal

Pengecatan

Total
$\operatorname{Rp} 125.000$

Rp $10.500+$

Rp 135.000

Rp 40.650

Rp 176.150

Pak Budi mengatakan biaya tersebut salah. Manakah yang salah?

Alifmatika: Jurnal Pendidikan dan Pembelajaran Matematika, Desember 2019, Vol. 1, No. 1 
Contoh 2. (untuk siswa SD/MI)

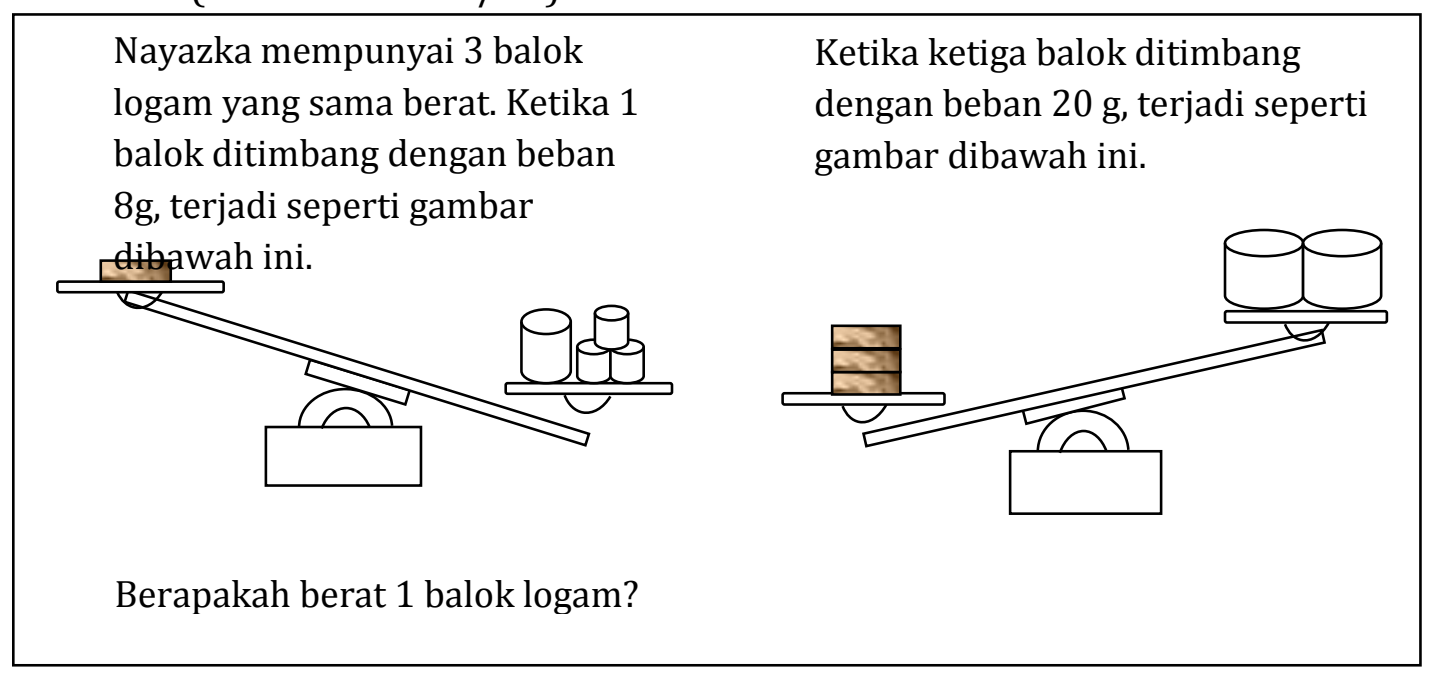

(Wardhani, 2014)

Contoh 3 (untuk siswa SMP/MTs)

Sebuah pipa perusahaan air minum berdiameter $170 \mathrm{~cm}$. Sekali waktu diketahui lebar permukaan penampang air $\mathrm{AB}$ adalah $80 \mathrm{~cm}$.

a. Hitunglah berapa kedalaman air PT?

b. Jika panjang pipa adalah 2000 meter dengan diameter sama di seluruh bagian dan kedalaman tetap seperti pada gambar di samping ini berapa volume $\left(^{*}\right)$ air dalam pipa tersebut?

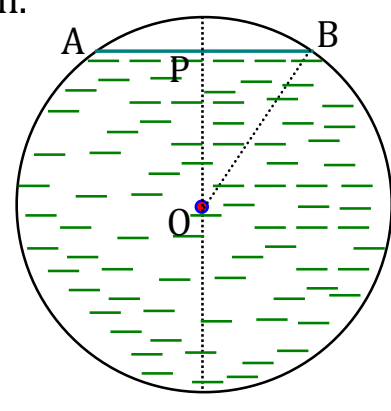

$\mathrm{T}$

\section{Penyelesaian:}

Untuk menyelsaikan permasalah di atas, jika gambarnya tidak tersedia, hanya mengandalkan cerita, maka akan ada dua kemungkinan keadaan. Namun jika gambernya sudah tersedia, seperti pada gambar di atas, maka akan hanya ada satu kemungkinan.

Karena $\mathrm{AB}=80 \mathrm{~cm}$, maka $\mathrm{PB}=40 \mathrm{~cm}$, sedangkan $\mathrm{OB}=1 / 2$ diameter atau $\mathrm{OB}=85$ $\mathrm{cm}$.

Siswa dapat meneliti bahwa $\triangle \mathrm{OPB}$ adalah segitiga siku-siku sehingga berlaku:

$\mathrm{OP}^{2}+\mathrm{PB}^{2}=\mathrm{OB}^{2}$

$\mathrm{OP}^{2}=\mathrm{OB}^{2}-\mathrm{PB}^{2}=85^{2}-40^{2}=(85+40)(85-40)=(125)(45)=5.5 .5 .5 .3 .3$

Sehingga $\mathrm{OP}=75 \mathrm{~cm}$.

Dengan demikian kedalaman PT $=85+75=160 \mathrm{~cm}$.

Mintalah siswa untuk mendiskusikan dengan teman sekelasnya berapa alternatif lain menentukan kedalaman air apabila lebar penampang air adalah $A B=80 \mathrm{~cm}$ (tanpa memperlihatkan gambar di atas)?

Alifmatika: Jurnal Pendidikan dan Pembelajaran Matematika, Desember 2019, Vol. 1, No. 1 
Untuk mengetahui berapa luas tembereng ATB, mula-mula kita cari luas Juring $\mathrm{OAB}$ Sin $\angle \mathrm{AOP}=8 / 17=0,4706$, sehingga

$<\mathrm{AOP}=28^{\circ} 07^{\prime}$

Sehingga $<\mathrm{AOB}=56^{\circ} 14^{\prime}$

Dengan demikian

Luas Juring AOB $=56 / 360 \times 22 / 7 \times 85 \times 85=3532,22$ $\mathrm{cm}^{2}$

Luas $\triangle \mathrm{AOB}=(80 \times 75) / 2=3000 \mathrm{~cm}^{2}$

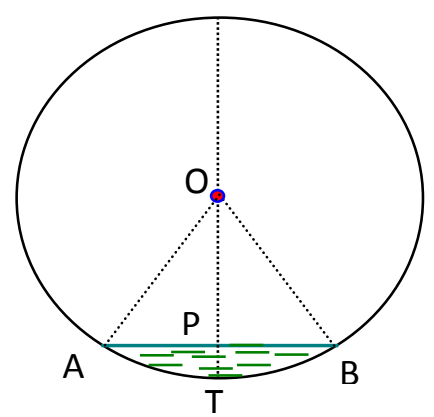

Karenanya luas penampang air ini adalah

$3532,22-3000=532,22 \mathrm{~cm}^{2}$

Dalam keadaan air seperti ini, volum air dalam pipa

2000 meter adalah $=532,22 \mathrm{~cm}^{2} \times 200000 \mathrm{~cm}$

$=106444000 \mathrm{~cm}^{3}$ atau $106444 \mathrm{dm}^{3}$ atau 106444

liter

Namun dalam posisi air seperti pada gambar pertama

Luas penampang air $=22 / 7 \times 85 \times 85-532,22 \mathrm{~cm}^{2}$

$$
=22174,92 \mathrm{~cm}^{2}
$$

Sehingga volum air dalam pipa 2000 meter adalah

(Turmudi, 2008)

Contoh 4. (untuk siswa SMA/MA/SMK)

Permasalahan meminimalkan waktu dengan kecepatan tertentu dan jarak tertentu, yang mengkombinasikan dua gerakan yaitu gerakan renang dan lari yang masing-masing memiliki kecepatan tertentu, peserta didik diminta untuk menentukan rentang waktu yang sekecil-kecilnya yang dapat ia tempuh, serta menentukan berapa jauh ia berenang dan berapa jauh ia berlari agar waktunya sekecil-kecilnya.

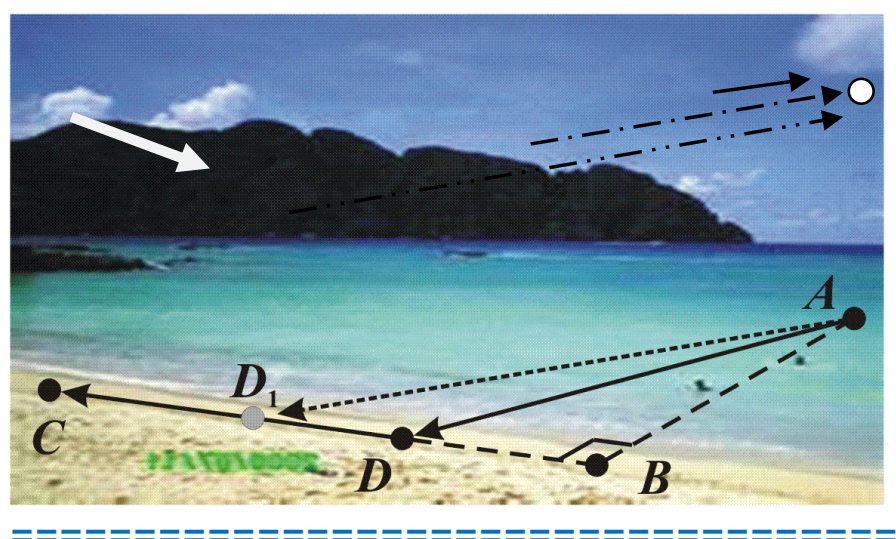

Alifmatika: Jurnal Pendidikan dan Pembelajaran Matematika, Desember 2019, Vol. 1, No. 1 
Ahmad berada di titik $A$, di sebuah perairan laut yang berjarak $4 \mathrm{~km}$ dari tepi pantai terdekat. Sebuah rumah dititik $C$ berjarak $12 \mathrm{~km}$ dari titik $B$ diketahui berasap yang diduga terjadi kebakaran. Ahmad ingin memberikan pertolongan untuk turut serta memadamkan asap yang ada di rumah $C$. Ia akan menjangkau suatu tempat di $C$ dengan cara berenang dengan kecepatan $6 \mathrm{~km} / \mathrm{jam}$ dan berlari dengan kecepatan $10 \mathrm{~km} / \mathrm{jam}$.

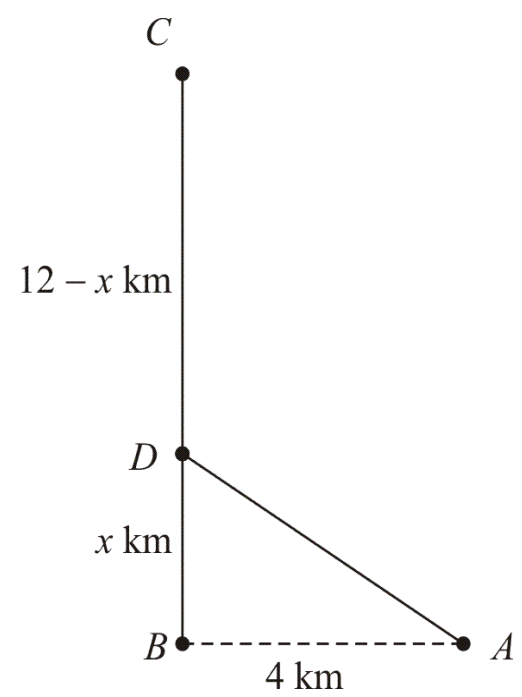

ニニ
Ahmad berenang dari titik $A$ menuju titik $D$ dengan kecepatan $6 \mathrm{~km} / \mathrm{jam}$ dan lari dari $D$ ke titik $C$ dengan kecepatan $10 \mathrm{~km} / \mathrm{jam}$. Jarak dari $B$ ke $C$ adalah $12 \mathrm{~km}$ dan jarak dari $A$ ke $B$ adalah $4 \mathrm{~km}$

Ia menghendaki agar waktu yang diperlukan untuk menjalani $A D$ dan $D C$ minimum, berapakah nilai minimum ini?

Mula-mula peserta didik hendaknya menerjemahkan permasalah di atas ke dalam model matematika agar peserta didik dapat mengetahui waktu minimal yang diperlukan.

Jelas bahwa nilai $x$ berada antara 0 dan 12. Jika $x=0$ artinya Ahmad harus renang sejauh $4 \mathrm{~km}$ dan lari sejauh $12 \mathrm{~km}$. Namun jika $x=12$ artinya Ahmad harus renang sejauh $A C$.

$A D=\sqrt{x^{2}+16} \mathrm{~km}$ dan $C D=(12-x) \mathrm{km}$, karenanya waktu untuk renang adalah $A D=\frac{1}{6} \sqrt{x^{2}+16} \mathrm{AD}=\left(\sqrt{ }\left(\mathrm{x} \mathrm{km} / \mathrm{jam}\right.\right.$ dan $C D=\frac{1}{10}(12-x) \mathrm{CD}=(12 \mathrm{~km} / \mathrm{jam}$. Misalkan waktu untuk menempuh $A D+D C$ adalah $T$, akibatnya $T=\frac{1}{6} \sqrt{x^{2}+16}+$ $\frac{1}{10}(12-x)$. Pada persamaan ini, ada tiga titik kritis yaitu Titik $x=0$ titik $x=12$ dan titik $x$ di mana $\frac{d T}{d x}=0$.

(a) Tentukan nilai $x$ yang menyebabkan $\frac{d T}{d x}=0$.

(b) Karena hanya ada dua kombinasi yaitu renang dan lari, salah satu kemungkinannya adalah renang seluruhnya, perlihatkanlah bahwa kalau renang seluruhnya, maka waktu yang diperlukan adalah 2,11 jam

(c) Ketika ia berenang $4 \mathrm{~km}$ dan lari $12 \mathrm{~km}$, perlihatkan bahwa ia membutuhkan waktu sebanyak 112 menit (1 jam 52 menit).

(d) Yang mana di antara a, b, dan c yang paling pendek waktunya.

Alifmatika: Jurnal Pendidikan dan Pembelajaran Matematika, Desember 2019, Vol. 1, No. 1 
Pengembangan Kurikulum Matematika untuk Meningkatkan....

Tabel 2 Ringkasan dari permasalahan di atas

\begin{tabular}{|c|c|c|c|c|}
\hline Rute & $\begin{array}{l}\text { Jarak tempuh } \\
\text { dinyatakan } \\
\text { dengan } x\end{array}$ & Jarak (km) & $\begin{array}{c}\text { Waktu } \\
\text { Tempuh } \\
\text { (dalam jam) }\end{array}$ & $\begin{array}{c}\text { Waktu } \\
\text { Tempuh } \\
\text { (dalam } \\
\text { menit) }\end{array}$ \\
\hline$A-B-C$ & $\begin{array}{c}\sqrt{x^{2}+16}+ \\
(12-x) \sqrt{ }(\mathrm{x} \\
\text { dengan } x=0\end{array}$ & $\begin{array}{c}(4+12) \mathrm{km}= \\
16 \mathrm{~km}\end{array}$ & $\frac{4}{6}+\frac{12}{10} \mathrm{jam}$ & 112 menit \\
\hline$A-D-C$ & $\begin{array}{c}\sqrt{x^{2}+16}+ \\
(12-x)\end{array}$ & $\begin{array}{c}(5+9) \mathrm{km}= \\
14 \mathrm{~km}\end{array}$ & $\frac{5}{6}+\frac{9}{10} \mathrm{jam}$ & 104 menit \\
\hline$A-C$ & $\begin{array}{c}\sqrt{x^{2}+16}+ \\
(12-x) \text { dengan } \\
x=12 \sqrt{(x}\end{array}$ & $\begin{array}{c}\sqrt{160} \approx \\
12,65 \sqrt{160} \approx \\
12,65 \mathrm{~km}\end{array}$ & $\begin{array}{c}\frac{1}{6} \sqrt{160} \sqrt{160 / 6} \\
\text { jam }\end{array}$ & 127 menit \\
\hline
\end{tabular}

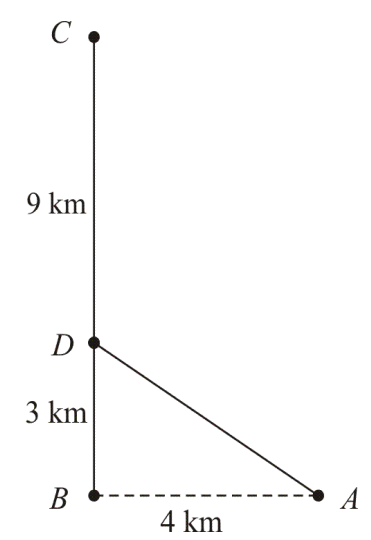

Jelas bahwa rute $A-D-C$ dengan $B D=3 \mathrm{~km}$ adalah rute yang paling efektif untuk menempuh perjalanan ini.

(Turmudi, 2009)

\section{KESIMPULAN DAN SARAN}

Diharapakan dengan penataan kompetensi yang tidak dibatasi oleh pemenggalan taksonomi proses berpikir dimana Keluasan dan kedalaman kompetensi dimensi pengetahuan untuk tingkat SD, SMP, SMA meliputi: faktual, konseptual, posedural, metakognitif dan dimensi proses berpikir meliputi: mengingat, memahami, menerapkan, menganalisis, mengevaluasi, mencinpta, sehingga dengan rumusan kompetensi matematika yang dapat mengembangkan kemampuan berpikir tingkat tinggi serta pembelajaran bukan sekedar menghapal rumus, namun dilakukan dengan melatih penalaran siswa dan pemecahan masaalah yang mengaitkan dengan masalah sehari-hari diharapkan nantinya terjadi peningkatan kemampuan siswa dalam penalaran dan pemecahan masalah dalam rangka meningkatkan kualitas siswa Indonesia dii era global ini. Diharapkan dalam pembelajaran matematika di kelas, para guru dapat menyusun atau menyajikan soal yang mendukung siswa untuk berpikir tingkat tinggi.

Alifmatika: Jurnal Pendidikan dan Pembelajaran Matematika, Desember 2019, Vol. 1, No. 1 


\section{DAFTAR PUSTAKA}

Abdusysyakin, A. A. (2006). Analisis Matematika Terhadap Filsafat Al-Quran. Malang: UIN-Malang.

As'ari, A. R., Tohir, M., Valentino, E., Imron, Z., \& Taufiq, I. (2017). Buku Guru Matematika (Revisi). Jakarta: Pusat Kurikulum dan Perbukuan, Balitbang, Kemendikbud.

Council, N. R. (1989). Curriculum and evaluation standards for school mathematics. National Council of Teachers of Mathematics.

Ferrini-Mundy, J., \& Martin, W. G. (2000). Principles and standards for school mathematics. Reston: National Council of Teachers of Mathematics (NCTM).

Kemdikbud. (2015). Modul Materi Pelatihan Kurikulum 2013. Jakarta: Kementerian Pendidikan dan Kebudayaan.

Leinwand, S. (2014). Principles to actions: Ensuring mathematical success for all. National Council of Teachers of Mathematics, Incorporated.

OECD. (2013). PISA 2015 Draft Mathematical Framework. Paris: OECD.org.

Suryadi, D. (2011). Pendidikan Matematika. Dalam Tim Pengembangan Ilmu Pendidikan Ilmu Dan Aplikasi Pendidikan Bagian Tiga. Bandung: PT Imperial Bhakti Utama.

Tohir, M. (2016). Hasil PISA Indonesia tahun 2015 mengalami peningkatan. Tersedia Online: Https://Matematohir.Wordpress.Com/2016/12/08/Hasil-PisaIndonesiatahun-2015-Mengalami-Peningkatan/ [08 Desember 2016], 1(1), 1-2.

Tohir, M. (2017). Pengembangan Bahan Ajar Olimpiade Matematika Berdasarkan Model Pemecahan Masalah untuk Meningkatkan Kemampuan Penalaran Matematis Siswa. In Tesis. Magister Pendidikan Matematika Universitas Jember. https://doi.org/10.13140/RG.2.2.31121.79200

Tohir, M. (2019). Hasil PISA Indonesia Tahun 2018 Turun Dibanding Tahun 2015. Retrieved December 3, 2019, from Paper of Matematohir website: https://matematohir.wordpress.com/2019/12/03/hasil-pisa-indonesiatahun-2018-turun-dibanding-tahun-2015/

Tohir, M., Susanto, Hobri, Suharto, \& Dafik. (2018). Students' Creative Thinking Skills in Solving Mathematics Olympiad Problems Based on Problem-Solving Polya and Krulik-Rudnick Model. Advanced Science Letters, 24(11), 83618364. https://doi.org/10.1166/asl.2018.12563

Turmudi. (2008). Buku Panduan Pendidik: Matematika SMP/MTs. Jakarta: Pusat Perbukuan, Departement Pendidikan National.

Turmudi. (2009). Buku Panduan Pendidik: Matematika SMA/MA. Jakarta: Pusat Perbukuan, Departement Pendidikan National.

Wardhani, S. (2014). Implementasi Kurikulum 2013 dalam Pembelajaran Matematika SMP/MTs. Bahan E-Training Guru Matematika SMP/MTs Tahun 2014. Yogyakarta: PPPPTK Matematika. 